\title{
A cyber safety poster/pamphlet comes to life as an object of governance
}

\author{
Trevor Van Weeren \\ Director \\ Merri Creek Productions \\ tvw@merricreek.com
}

Keywords: Objects of governance, Aboriginal, cyber safety, Serres, Yolnu

Figure 1: Cyber safety poster/pamphlet (front)

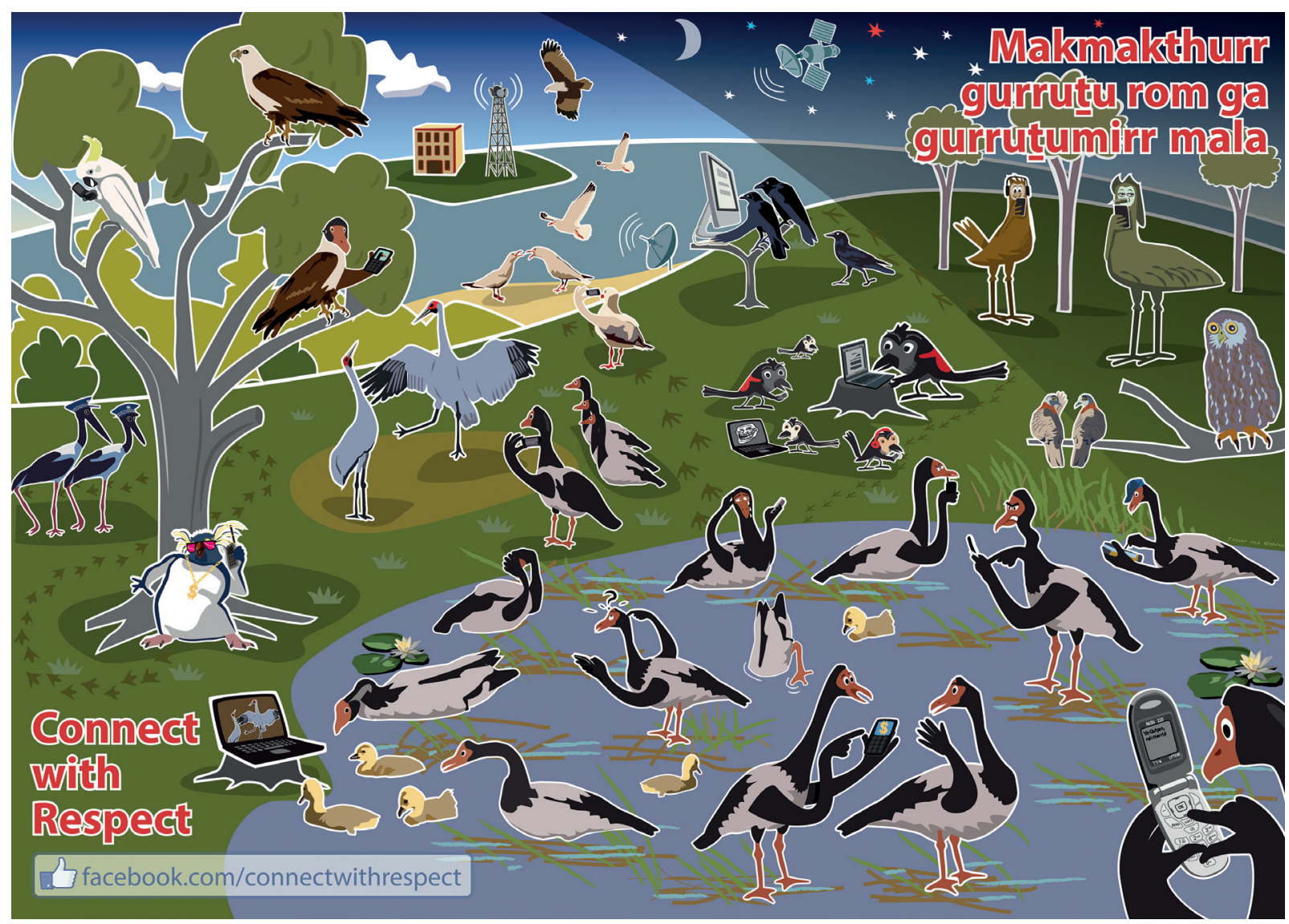


Figure 2: Cyber safety poster/pamphlet (back)

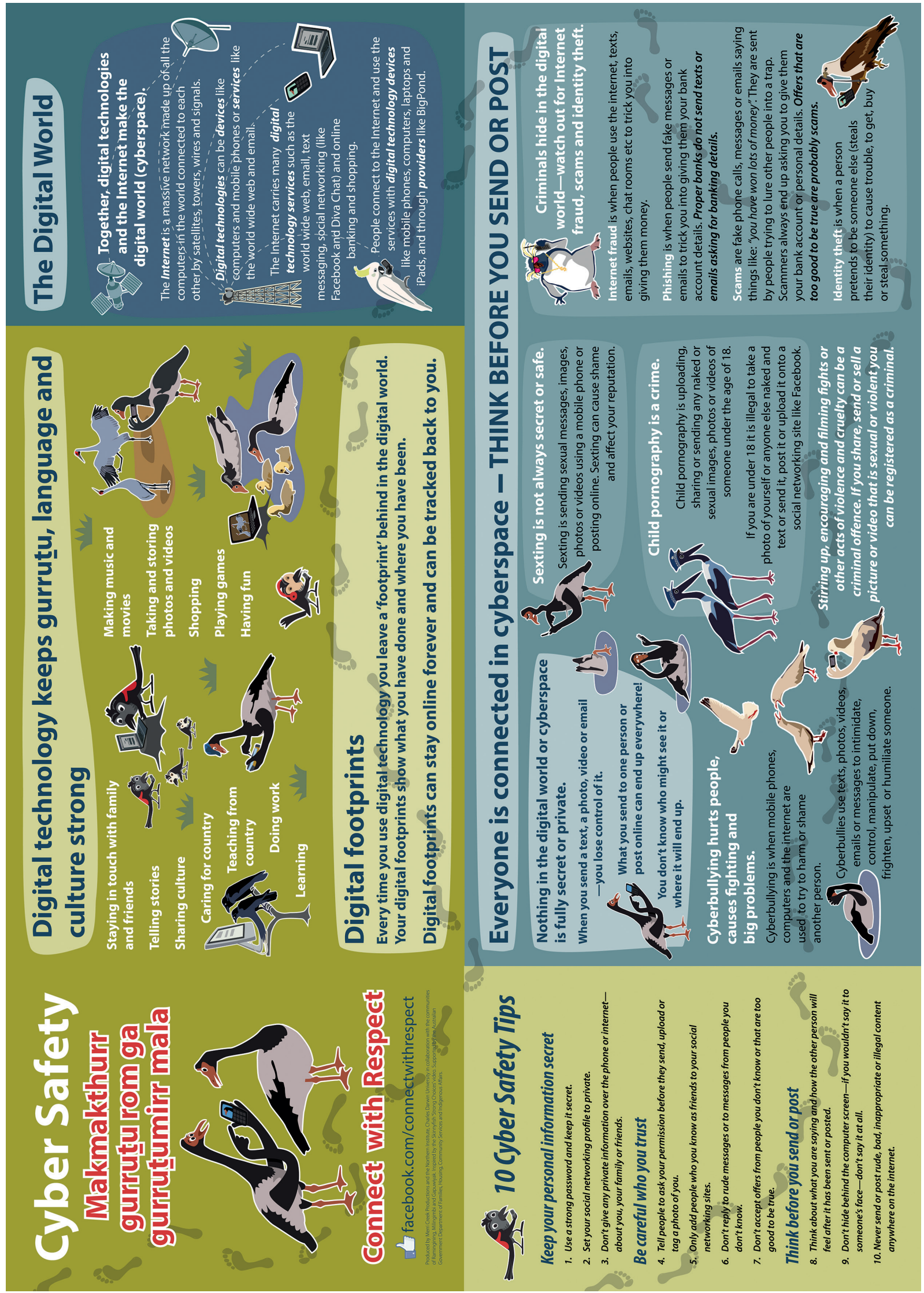


During their end of financial year budget sessions in 2012 the East Arnhem Land regional arm of the Government department responsible for Indigenous Affairs, earmarked some money and created a project concept to address feedback given at community-based 'Stronger Futures' consultations. I begin by imagining 'Community Feedback' like the ball Serres' (1995) has us imagining in drawing attention to the relation between a ball and children playing a game. 'Community feedback' might be imagined as an object of governance - like the ball that skillful children playing a game are 'ordered around by.' Accordingly, the actions of the skillful public servants involved in the 'Stronger Futures' consultations setting about their 'game' brought to life another object of governance : The Makmakthurr gurrutu rom ga gurrutumirri mala (Connect with Respect) - Cyber safety poster/pamphlet.

In the 'Stronger Futures' discussions, community elders in three Yolnu Aboriginal communities spoke of their concerns and worries about what was happening with new technology, and in particular, mobile phones. The government workers were told that the younger generations were using the new technologies in ways that were having serious consequences within the community. These consequences manifested in various conflicts and trouble within social networks and cultural relations. The public servants 'translated' these discussions into a small program to support communities to work through some of these issues. The project was given a catchy name, 'Talking Strong Staying Safe' (TSSS).

I work with a group of academics and practitioners in the Northern Institute at Charles Darwin University. We have many years of experience working in Arnhem Land and with Yolnu people. We are now marketing ourselves with the moniker GroundUP in an attempt to articulate the methods and theoretical underpinnings of the way we like to work. On the strength of our work and the relationships we have made with government and Yolnu, our group was contracted to deliver the program. This is the context that the posters were 'brought to life'.

In our projects, GroundUP is committed to methods whereby projects are built from the ground up, with and alongside the people it targets. We actively try to avoid a top down approach. GroundUP seeks to privilege local knowledge, collaboration and knowledge generation through exploring problems. We find people to work with, work out what skills and knowledge we can all bring to the project, and negotiate how it will be implemented and for whose benefit. We document our activities carefully and develop our resources and strategies collaboratively.

The TSSS project work started with a conventional 'desktop research phase' collecting current Cyber Safety resources and materials. We sifted through the textual material and simplified the main concepts and messages into plain English that we thought would be appropriate to the context.

Following the desktop research, I visited communities and started conversations, listening to what people were concerned about. What were the local issues around cyber safety? We decided to create a poster/pamphlet. Having a physical picture-based poster/pamphlet would give us an object we could use, to generate conversations around the issues. A poster/ pamphlet could become a participant in an imagined future conversation with parents, youth, and teachers. I suppose, the 'we' who decided here were the consultants, but it was not solely us - the texts we'd dredged up off the internet, and our Aboriginal friends and acquaintances are also part of that 'we'. We would use these posters in workshops, at schools; share them in public spaces and visit individuals and families. We already had experience making posters as conversation generating tools.

Somewhat unexpectedly the discussions and early sketches for the poster using images of people was abandoned for a version being populated by birds; a landscape of birds using phones and computers, including all the possible scenarios of using technology we had 
identified as important. We thought using birds could keep the issues in an imagined (nonhuman) space, and add a level of safety for people to discuss private issues. The figures of birds-in-landscape carried no explanation with them. The idea was that we would spread it around and generate on-the-spot stories about what was happening amongst the bird characters. The back-side of the poster of a landscape filled with digital device- using birds, would have concise explanations and imagery that linked back to the landscape view. If people could read English they could find explanation of hazards and safety issues in the poster.

I brought the text for the back-side of the poster to a translator. I showed what we had developed with its accompanying text. We translated a few pages from English to a Yolnu language together. I realised, what we had thought was heavily edited and simplified English was still too detailed and full of assumptions. Our initial aim with the text and accompanying pictures was to provide some pointers to the underneath story and the implicit assumptions behind many of the concepts relating to new technologies.

On the surface level, the digital technologies and the functions they perform seem straight forward, but how the devices worked socially, the traces they left behind and other hidden discourses, were what we wanted to tease out in the written text. The translation process turned English points about Cyber Safety into awkward word by word translations expressed in a language where many of the concepts just didn't seem to have life, and the terms we found ourselves using were becoming instructional do's and don'ts.

As an object of governance, an expression of the practices of government officers and of our practices as contracted consultants, the poster/pamphlet would introduce some key ideas, suggest some scenarios, and present some facts. As we 'worked' the illustrations and text with people, we showed them how they could use it with family members and encouraged people to take a copy home. We imagined this would allow space for people to find their own methods and processes to incorporate new knowledge, new categories and new practices into their already established governance practices.

Inappropriate mobile phone usage and other cyber safety issues are generally seen by Aboriginal community members as an internal community matter: boys and girls are naughty; people do the wrong thing; kinship laws are forgotten etc. One aspect that we weren't prepared for was that many Elder people talked about how this technology had dropped into their communities without warning and without proper explanation of how it worked (the underneath story). Of course people would get things wrong if they weren't aware of 'digital footprints', the persistency of life in the digital world, and especially threats (such as scams) coming into the community via these new technologies. We realised that we needed to include in our conversations that the issues we were talking about in the Talking Strong, Staying Safe project were felt as problems across all classes and places in Australia and around the world. This was not a problem unique to Aboriginal communities.

To keep the conversations going, we kept foregrounding that the new technologies and processes were opportunities to strengthen the very things that they were also eroding. For example, with kinship, new communication technologies exposed the kinship system to new and inappropriate communication practices (e.g., Facebook, DivaChat) but that at the same time it allowed the same kinship networks to be strengthened across distance and with multimedia.

Typically, modern posters are about communicating a message through mass production and distribution enabled by the low cost of production. For over two hundred years, posters have been displayed in public places all over the world. They are designed to attract attention, making us aware of a political viewpoint, some new information, or encouraging us to subscribe to a particular product or service. Our poster/pamphlet could be categorised in a particular class. It 
is designed to demonstrate and show examples and concepts in an educational, awarenessraising, information-sharing and most importantly, by conversation-generating modes. The poster could also be included in a class of objects designed to communicate across language and cultural divides.

So a poster seeks to communicate visually and can include text. In this case the poster worked in two ways, as a hand-out pamphlet and a hang-able poster. It worked as an intermediary between people to generate conversations. I remember posting a few posters up outside a store. People stopped to have a look, they said hello and asked what it was all about, all sorts of conversations started up. Some conversations eventually got around to what the poster was there for, to generate stories around Cyber Safety, ask advice, seek clarification, can I have one to take home, good times.

I remember another time at another location, we went to talk to a couple of 'naughty' boys who were apparently hard to talk to about anything, and were known to be causing problems via new technologies. The poster in its pamphlet form (and the role of pamphlet-giver-aspart-of-government-project we had) allowed us an opportunity to engage with them via the object of the poster. They were squirming the whole time, but my Yolnu co-worker relished the power the poster/pamphlet had given him for that interaction to be possible, as a culturally appropriate 'not shaming/disciplinary' encounter.

Two years later the poster, albeit spotted with fly dirt and rather tattered, can still be seen in one or two places around the communities which were its target audience. It sits there as an object of governance, possibly now invisible to most, but nevertheless still a possible agent eliciting responsible engagement with digital technology. Because of my involvement in the project, some people recognise me as the cyber safety expert and ask me for advice. I still have a few posters left and am still handing them out. The issues around social media seemed to have diminished, but the problems of scams are on the rise.

\section{References}

Serres, M. (1995). Angels. A Modern Myth (Edition 1009, September). Paris, France: Flammarion. 